\title{
Parasitic Loads and Growth Performance of Goats and Kids under Sequential and Mixed Species Grazing with Cattle at a Constant Stocking Rate
}

\author{
${ }^{1}$ Renita Woods Marshall, ${ }^{1}$ Sebhatu Gebrelul, \\ ${ }^{1}$ Shonta Manuel, ${ }^{1}$ Calvin Adams and ${ }^{2}$ Yemane Ghebreiyessus \\ ${ }^{I}$ Department of Animal Sciences, \\ Southern University Agricultural Research and Extension Center, \\ LA 70813, Baton Rouge, United States \\ ${ }^{2}$ Department of Urban Forestry, \\ Southern University and A and M College, LA 70813, Baton Rouge, United States
}

Article history

Received: 03-03-2015

Revised: $15-04-2015$

Accepted: 11-05-2015

Corresponding Author: Renita Woods Marshall Department of Animal Sciences, Southern University Agricultural Research and Extension Center, United States Email: renita_marshall@suagcenter.com

\section{Introduction}

Controlled grazing is the process of matching plant and animal requirements in order to increase the harvest of solar energy by plants, plants by animals and animal Count, Mixed Grazing

\begin{abstract}
The objective of this study was to evaluate the effects of sequential and mixed species grazing on parasitic loads and growth performance of goat kids. The study was conducted between June and October, 2013. Forty eight (48) "Spanish" kids and 28 Brangus calves were randomly divided into four treatment groups; goats grazing alone (GOA, control), Goats Followed by Cattle (GFC), Cattle Followed by Goats (CFG) and, cattle and goats mixed (MXD) grazing. Each pasture was sub-divided into 8 grazing paddocks to facilitate intensive grazing. Each of the 8-ha grazing pasture was sub-divided into two replications and eight paddocks. Animals were moved to a new paddock twice a week ( $3.5 \mathrm{~d}$ rotation). The initial stocking rate was based approximately upon 0.8 ha per cow that would allow five cows per replication. Body Weights $(\mathrm{BW})$, body condition score $(1=$ thin, $5=$ fat, BCS), Famacha ${ }^{(}$scores $(1=$ pink, healthy eye, $5=$ white, anemic) and fecal and blood samples were taken bi-weekly. Fecal and blood samples were analyzed in the lab for fecal egg count in eggs per gram (FEC) and Packed Cell Volume (PCV) percentages. Data was statistically analyzed using SAS's MIXED procedure and correlation coefficients were determined among the measurements. Differences $(\mathrm{p}<0.05)$ among treatment groups were observed where kids in GOA group were lighter in weight $(13.2 \pm 0.0$ Vs. $17.3 \pm 0.6 \mathrm{~kg})$ and less conditioned (1.9 \pm 0.07 Vs. $2.3 \pm 0.07)$ than the CFG, GFC and MXD groups combined. No difference in Famacha ${ }^{\circ}$ scores (2.3 \pm 0.07 Vs. 2.3 \pm 0.06$)$ and PCV percentages (29.4 \pm 0.8 Vs $27.7 \pm 0.8)$ were observed between GFC and MXD groups. Male kids were about $1 \mathrm{~kg}$ heavier than female kids. BW was positively $(\mathrm{p}<0.05)$ correlated with $\mathrm{BCS}, \mathrm{HG}, \mathrm{PCV}$ and negatively with FEC. BCS was positively $(\mathrm{p}<0.05)$ correlated with $\mathrm{HG}, \mathrm{PCV}$ and negatively with FEC. After the eighth week of the study, kids in GFC and MXD groups had lower Famacha ${ }^{\odot}$ scores and higher PCV levels than kids in GOA and CFG groups. Overall, compared to kids grazing alone, mixed and sequential grazing kids had higher BCS, BW and PCV levels and lower Famacha ${ }^{\odot}$ scores.
\end{abstract}

Keywords: Growth Performance, Goats, Sequential Grazing, Fecal Egg

products from the land. The principle behind controlled grazing is that the animals are not scattered over a large area, but are confined to an area and are forced to utilize all the forage in that area before being moved to a new area. A large pasture is subdivided into several 
paddocks. Animals are grouped and rotated through a series of paddocks, feasting en masse on the tender forage in one paddock while the other paddocks rest to supply high quality forage later. Rotational grazing increased beef production per hectare by increasing stocking rate without decreasing daily gain or diet quality compared with a continuous grazing system (Bertelsen et al., 1993).

The efficient utilization of available forage through sequential and mixed-grazing systems may enhance animal performances and increases farm income per unit area of production. The objective of mixed grazing is to increase whole farm productivity while enhancing efficient utilization of forage resources. Several studies indicate that mixed grazing increases meat production compared to single species grazing. This advantage is usually caused by both increased individual animal performance and increased carrying capacity (Horák et al., 1999). Despite the potential for increased efficiency in pasture utilization and increased economic returns at farm level, mixedgrazing is not widely practiced, especially by small farms. In addition, cattle and goats grazing system is a new farming practice in Louisiana and the U.S.

In a study to determine the effect of mixed-species grazing on the growth of cattle and goats at Southern University, Baton Rouge, Louisiana, 28 Brangus cows and 80 Spanish goats were randomly assigned to continuous or rotational grazing systems and were allowed to graze alone or mixed with the other species (Gebrelul et al., 2004; Chappell et al., 2004; Ghebreiyessus et al., 2007; Marshall et al., 2009). Cattle grazing alone were $64.7 \mathrm{~kg}$ heavier $(\mathrm{p}<0.05)$ than those grazing with goats under continuous grazing, but the differences in weights were not significant under rotational grazing. Goats grazing with cattle under rotational grazing averaged $35.8 \pm 1.2 \mathrm{~kg}$ while those in continuous system averaged $33.7 \pm 1.3 \mathrm{~kg}$, the difference being significant $(\mathrm{p}<0.05)$.

Management practices such as pasture rotation and mixed livestock species grazing have proved useful in animal production and parasite management. Nolan and Connolly (1989) found that mixed grazing significantly increased average daily gain of lambs to weaning and to drafting from 246 to $265 \mathrm{~g}$ and from 211 to $223 \mathrm{~g}$, respectively. Steer ADG for this period was increased from 1.42 to $1.52 \mathrm{~kg}$ and from 0.950 to $1.094 \mathrm{~kg}$, respectively. In this study, 10 to $13 \%$ more area was required for mono-grazing to produce the same grazing season output as under mixed grazing. The authors observed that sheep preferentially graze the soiled forage around steer dung pats which steers largely refuse, particularly close to the time of dung deposition. For at least six weeks following dung deposition the forage surrounding the dung had a much higher dry matter digestibility under mixed grazing than the unsoiled fraction.
In the absence of off-farm income, small-scale farm families cannot earn an income comparable to the nation's average per capita income, even if they adopt the most efficient practices in conventional (traditional) agriculture. However, production using a combination of conventional and specialty enterprises may maximize the use of available resources and allow the small-scale farm producer to make sufficient income to care for the family. Goats are excellent browsers and can utilize pasture, range and forest lands extremely well to meet their nutritional needs. In addition, mixed-species grazing (i.e., cattle and goats) could prove beneficial; however, reliable documentation or research is lacking.

The overall aim of this project was to conduct research and demonstrate effective pasture and grazing management for both single and multi-species livestock production. This research will provide information to assist small scale producers in increasing their production and economic base by utilizing available natural and farm resources through multiple grazing systems.

\section{Materials and Methods}

\section{Experimental Site, Design and Plot Management}

The experiment was conducted at the Southern University Agricultural Research and Extension Center Experiment Station in Baton Rouge, LA. The soil is silt loam soil, poorly drained and slowly permeable, with almost zero slopes. The plots comprised of 'improved' pastures and consisting mostly of perennial ryegrass, bermuda grass and tall fescue as permanent pastures.

Approximately 26 ha was divided into one 2 ha and three 8-ha Bermuda-grass (Cynodon dactylon) pastures. Each pasture was sub-divided into 8 grazing paddocks to facilitate intensive grazing using electric fencing for a replication. The one 2-ha pasture was used for the GOA treatment and was divided into two blocks (replicated pastures). Each of the 8-ha grazing pasture was subdivided into two replications and eight paddocks.

Goats moved to a new paddock twice a week $(3.5 \mathrm{~d}$ rotation). The initial stocking rate for goats was based approximately upon 0.1 ha per doe, allowing 10 does per replication. Cattle moved to a new paddock every $3.5 \mathrm{~d}$. The initial stocking rate was based approximately upon 0.8 ha per cow that would allow five cows per replication.

Details of the experimental layout and location of pastures at the SU Research Station are shown in Fig. 1.

\section{Animals}

Forty eight (48) "Spanish" kids and 28 Brangus calves were randomly divided into four treatments; goats alone rotation (GOA, control), Goats Followed by Cattle (GFC), Cattle Followed by Goats (CFG) and, cattle and goats together in Mixed Grazing (MXD). 


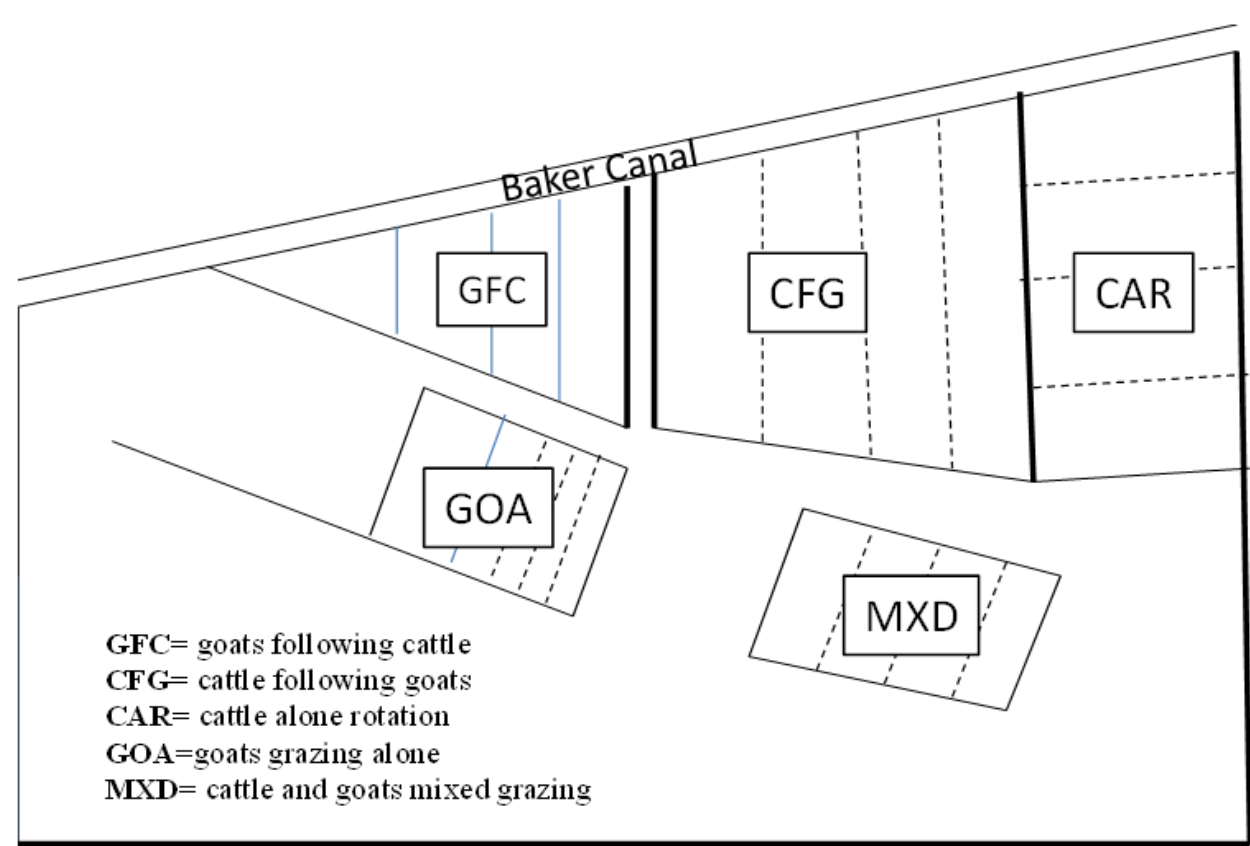

Fig. 1. Experimental plots layout

Brangus cattle were used for this project for the following reasons; (1) Angus cattle have a faster growth rate and produce a high quality carcass, (2) Brahman cattle have a higher tolerance to the high temperatures, humidity and insects in the South. The goat herd consisted of improved Spanish meat goat does. They are valued for their ability to adapt quickly to varying grazing conditions as well as their hardiness. Boer sires were used to produce heavier, faster growing kids.

The animals were fed hay and supplements until the ryegrass was ready to be grazed. Animals had free access to water, salt and mineral mix at all times. Experimental animals were provided with supplemental feed in times of unexpected drought. Bulls were placed in the treatment pastures during a 60-day breeding season (from May 1 to June 30 each year). The bulls were rotated to a different pasture each week during the breeding season to remove the effects the sires might have on treatments. Any cow that failed to produce a live calf was replaced. Calves were removed from the cows when they reach 210 days of age and placed on a different pasture until they reached an average weight of about $365 \mathrm{~kg}$.

The breeding season for goats was restricted to September through early October to coincide with the ryegrass over-seeding of the pastures. During this time, does were confined in pens at the beef barn for pen breeding. Four Boer bucks were used for breeding and bucks were rotated across the pens to neutralize sire effects that may influence performance. Any doe that failed to produce a live kid or kids was replaced. Standard animal husbandry practices (identification, vaccination, disbudding, castrating, etc.) were performed before kids were weaned at approximately three months of age. At weaning, kids were placed on pastures during the day and penned in the beef barn at night for 4-6 weeks. They were then moved to new pastures until they reached a weight range of 30-35 kg. Doelings served as replacements for the main herd in the grazing experiment.

\section{Variables Measured}

Live Body Weights (BW), body condition score (BCS, 1=thin, 5=fat, BCS, Villaquiran et al., 2004), Famacha $^{\circ}$ scores (1=pink, healthy eye, $5=$ white, anemic), fecal and blood samples were taken bi-weekly from June to October, 2013. Famacha ${ }^{\odot}$ scores of goats were determined by observing the color of the mucous membranes of the lower eyelid. Famacha ${ }^{\circ}$ has 5 levels, 1 (red, non-anemic) to 5 (white, severely anemic). Goats with Famacha ${ }^{\mathcal{O}}$ scores of 4 or higher were chosen to be dewormed. Goats on each plot were treated with Ivermectin and then again 28 days later if needed based upon fecal egg counts and Famacha ${ }^{(}$ scores. Fecal egg counts were measured in goats prior to each anthelmentic treatment.

\section{Sample, Data Collection and Processing}

In order to evaluate animal performance in the mixed/sequential grazing experiment, the following measurements were recorded (as applicable) from each animal: Approximate breeding date, kidding/calving date, birth weight, number of offspring born, weaning weight and age at puberty. Animals were weighed at the initiation of the study and every 14 days thereafter. Body conditions scores (1-5 system) and fecal samples were 
also taken every 14 days. Body weights were determined using a sheep and goat scales that are built with a short wheel base design as well as pneumatic tires in order to enhance maneuverability.

Fecal and blood samples from each grazing regiment were analyzed to determine fecal egg counts per gram of sample (FEC) and Packed Cell Volume (PCV) percentages. Collected feces were evaluated to determine the number of parasite eggs excreted per gram of feces (epg). Fecal samples were transported and stored at $4{ }^{\circ} \mathrm{C}$, prior to processing within a week of collection. Fecal samples were homogenized to uniformly distribute the eggs throughout the feces prior to FEC determination using the Modified McMaster Test with one egg representing 50 eggs per gram (epg) of fresh feces. Fecal Egg Counts (FEC) were determined from feces collected, at the same time on each collection day, immediately prior to treatment with anthelmintics, directly from the rectum of each doe. Two grams of feces was placed into a $50 \mathrm{~mL}$ centrifuge tube and filled to $30 \mathrm{~mL}$ with salt solution. Samples were allowed to soak for a few minutes broken up (fecal pellets) and then mixed. With the use of a pipette, both chambers of the slide were filled. All eggs inside of the grid area were counted using $10 \mathrm{X}$ objectives. Only trichostrongyle eggs were counted. Total egg count (both chambers) X 50 equaled FEC (eggs per gram).

Blood was collected from the jugular vein with the use of the vacutainer system with a 21 gauge needle and a non-additive (red top) blood collection tube. The collected blood was analyzed in the lab for PCV determination. PCV is that percentage of blood that is red blood cells. The normal PCV percentage for goats is approximately $30 \%$. Twenty percent and lower indicates signs of anemia.

Body condition scores were assigned by physically evaluating the area of the back behind the ribs containing the loin. Scoring in this area is based on determining the amount of muscle and fat over and around the vertebrae. This was accomplished by running our hand over this area and trying to grasp the sternum (breastbone). Scoring in this area was based upon the amount of fat that can be pinched (Langston University).

\section{Data Analysis}

Data was analyzed using SAS's MIXED procedure and regression and correlation analysis (SAS Institute Inc., 2011). Dependent variables included Fecal Egg Counts (FEC), Packed Cell Volume (PCV), Body Weights (BW), Famacha ${ }^{\odot}$ scores and Body Condition Scores (BCS). The main effects in the MIXED model were grazing treatments (GOA, GFC, CFG and MXD), gender of kids, replications, weigh dates and interactions. All animals in the study and weighing date were considered random effects and treated in the model accordingly. Contrast statements of interest were included to test various hypotheses. These included cattle grazing with goats Vs cattle grazing alone, goats grazing with cattle Vs goat grazing alone, etc.

The general model is:

$$
\mathrm{Y}_{\mathrm{ijklm}}=\mu+\mathrm{G}_{\mathrm{i}}+\mathrm{M}_{\mathrm{j}}+\mathrm{A}_{\mathrm{k}}+\mathrm{GM}_{\mathrm{ij}}+\mathrm{R}_{\mathrm{l}}+\varepsilon_{\mathrm{ijklm}}
$$

Where:

$\mathrm{Y}_{\mathrm{ijklm}}=$ The dependent variable (BW, FS, BCS, PCV and FEC)

$\mu \quad=$ The overall (constant) mean

$\mathrm{G}_{\mathrm{i}} \quad=$ The fixed effect of the $\mathrm{i}^{\mathrm{th}}$ grazing type, $\mathrm{i}=1,2$

$\mathrm{M}_{\mathrm{j}} \quad$ = The fixed effect of the $\mathrm{j}^{\text {th }}$ specie type grazing, $\mathrm{j}=1,2$

$\mathrm{A}_{\mathrm{k}}=$ Random animal (goat or cow) effect

$\mathrm{GM}_{\mathrm{ij}}=$ The interactions of $\mathrm{G}$ and $\mathrm{M}$

$\mathrm{R}_{1}=$ The random effect of the $\mathrm{k}^{\text {th }}$ month effect

$\varepsilon_{\mathrm{ijklm}}=$ The uncontrollable variation, assumed to be Normally and Independently (NID) distributed, with $\mu=0$ and $\sigma=1$

Correlation and chi-square analysis were also used to determine relationships and percentages of the various non-parametric parameters measured in this project.

\section{Results}

Least square means and standard errors for BW, BCS, Famacha ${ }^{\odot}$ scores and PCV percentages for kids in the four treatments groups are shown in Table 1.

Table 1. Least square means of body weights, body condition scores, Famacha ${ }^{\mathcal{C}}$ scores and packed cell volume of kid in different grazing treatments

\begin{tabular}{|c|c|c|c|c|}
\hline Treatment $^{\dagger}$ & $\mathrm{BW}$ & BCS & $\begin{array}{l}\text { Famacha } \subset \\
\text { scores }\end{array}$ & PCV \\
\hline GOA & $13.2 \pm 0.59 \mathrm{a}^{\dagger}$ & $1.9 \pm 0.07 \mathrm{a}$ & $2.7 \pm 0.07 \mathrm{a}$ & $23.0 \pm 0.77 \mathrm{a}$ \\
\hline $\mathrm{CFG}$ & $16.2 \pm 0.55 b$ & $2.1 \pm 0.06 \mathrm{~b}$ & $2.9 \pm 0.07 \mathrm{a}$ & $22.1 \pm 0.71 \mathrm{a}$ \\
\hline GFC & $18.4 \pm 0.57 \mathrm{~b}$ & $2.3 \pm 0.06 \mathrm{~b}$ & $2.3 \pm 0.07 \mathrm{~b}$ & $29.4 \pm 0.73 b$ \\
\hline MXD & $17.4 \pm 0.56 \mathrm{~b}$ & $2.3 \pm 0.07 \mathrm{~b}$ & $2.3 \pm 0.07 \mathrm{~b}$ & $27.7 \pm 0.74 b$ \\
\hline
\end{tabular}

$\uparrow \mathrm{GOA}=$ Goats Alone; $\mathrm{CFG}=$ Cattle Followed by Cattle; GFC, Goats Followed By Cattle; MXD= Mixed Grazing;

$\dagger \dagger$ Means followed by the same letter do not differ $(p>0.05)$

Table 2. Partial correlation coefficients ${ }^{\dagger}$ of BW, BCS, Famacha $^{\odot}$ score, HG, PCV and FEC from the Error SSCP Matrix

\begin{tabular}{llllll}
\hline \multicolumn{1}{c}{ BCS $^{2}$} & FS $^{\odot}$ & HG & PCV & FEC \\
\hline BW & $0.626^{* * *}$ & -0.033 & $0.772^{* * *}$ & $0.189^{* *}$ & $-0.156^{*}$ \\
BCS & -0.071 & $0.538^{* * *}$ & $0.208^{* *}$ & $-0.194^{* *}$ \\
FS $^{\mathcal{O}}$ & & $0.139^{*}$ & -0.074 & 0.032 \\
HG & & & $0.148^{*}$ & $-0.135^{*}$ \\
PCV & & & & $-0.157^{*}$ \\
\hline
\end{tabular}

$\dagger * * *=\mathrm{p}<0.001 ; * *=\mathrm{p}<0.01 ; *=\mathrm{p}<0.05, \mathrm{BW}=$ Live Body

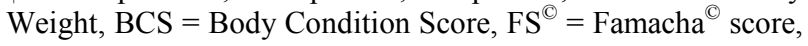
$\mathrm{PCV}=$ Packed Cell Volume percent; FEC $=$ Fecal Egg Count in epg HG = Heart Girth 


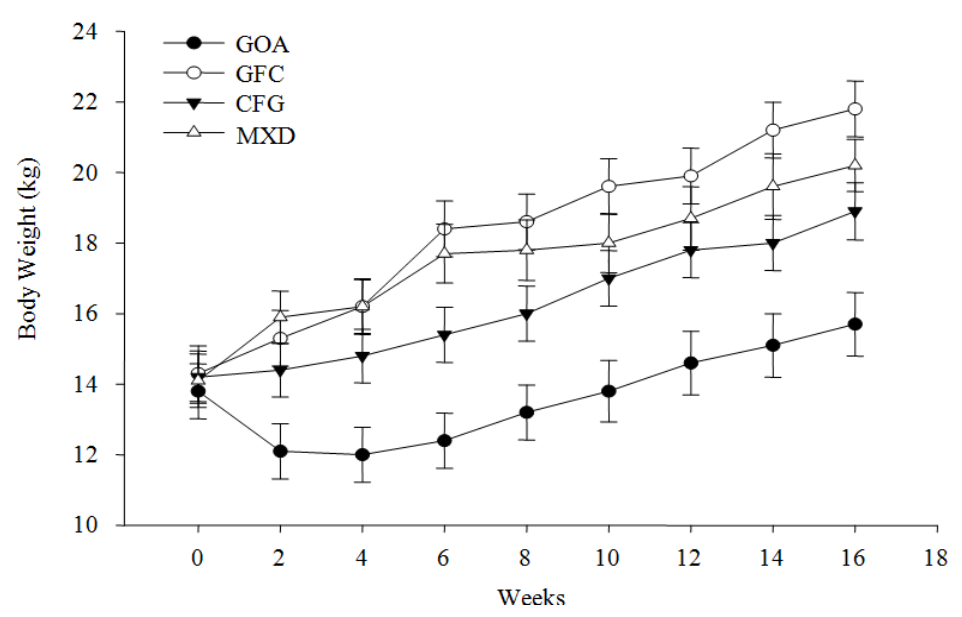

Fig. 2. Bi-Weekly Kid Body Weights from June (inital) to October for four treatment groups

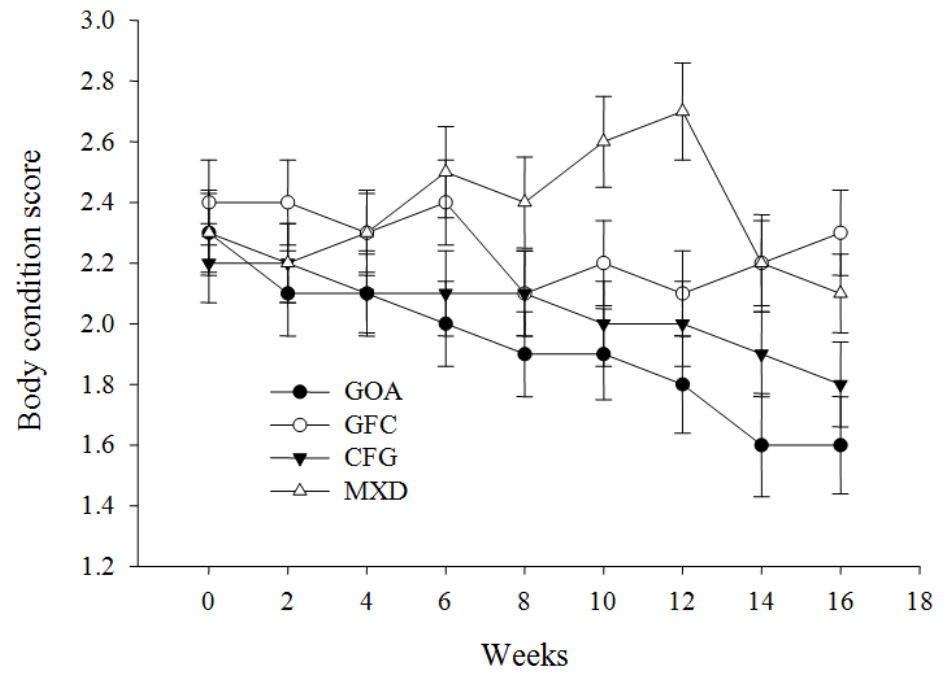

Fig. 3. Bi-Weekly kid Body Conditions Scores from June (initial) to October for four grazing treatments groups

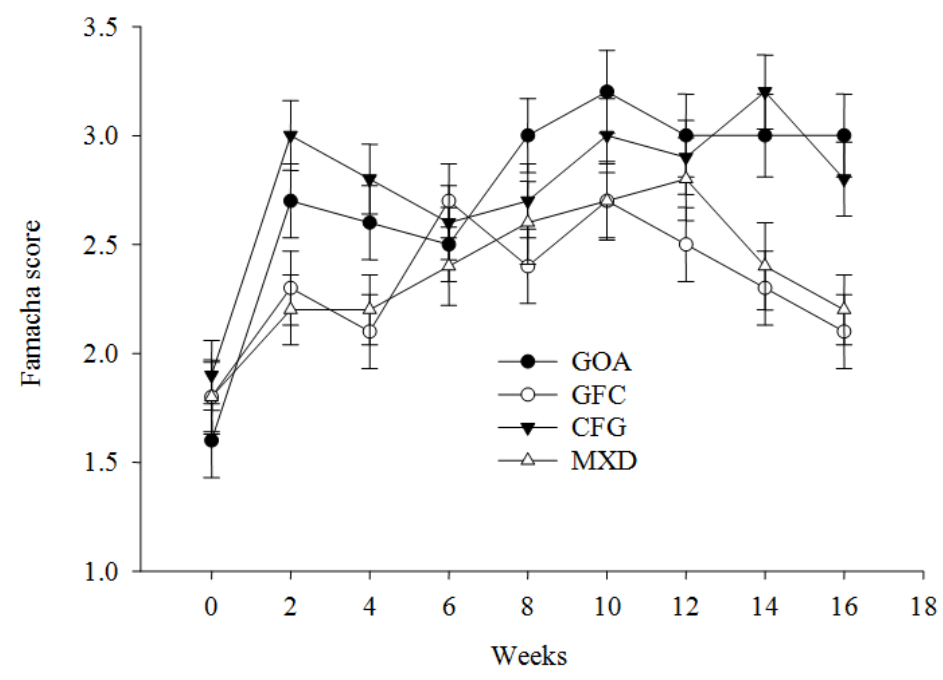

Fig. 4. Bi-Weekly Kid Famacha Scores from June (initial) to October for four treatment groups 


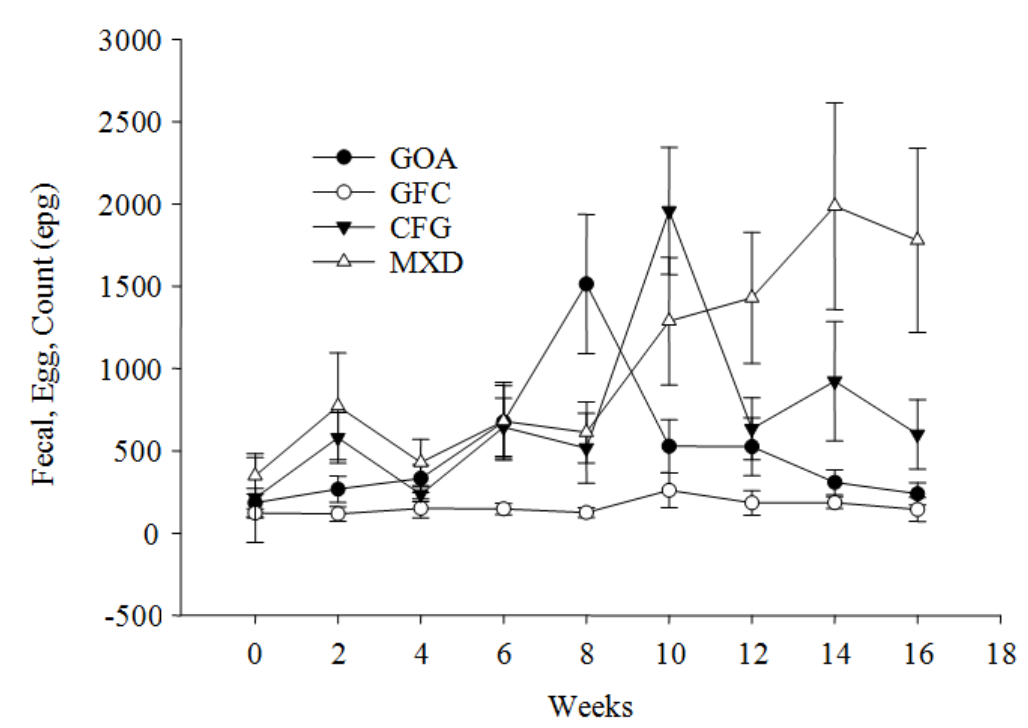

Fig. 5. Bi-Weekly Kid Fecal Egg Count, epg from June (initial) to October for Four Grazing Treatments

There were significant differences $(\mathrm{p}<0.05)$ among grazing treatments for $\mathrm{BW}, \mathrm{BCS}$, Famacha ${ }^{\circ}$ score and PCV percentages in kids but not on FEC due to large variability in the measurement. BW and BCS in kids in GOA group were lower $(p<0.05)$ than the other groups. Famacha ${ }^{\circ}$ score and PCV values did not differ $(p>0.05)$ in GOA and CFG groups but were different $(\mathrm{p}<0.05)$ than the GFG and MXD groups. Except for BW, gender had no effect on BCS, Famacha ${ }^{\circ}$ score or PCV percentages. Male kids were about $1 \mathrm{~kg}$ heavier $(16.9 \pm 0.4 \mathrm{Vs} 15.7 \pm 0.3 \mathrm{~kg})$ than female kids.

The coefficients of correlations derived from the error SSCP matrix are given on Table 2 . BW was positively with BCS $(p<0.001)$, HG $(p<0.001)$, PCV $(p<0.01)$ and negatively with FEC $(p<0.05)$. BCS was positively correlated with HG, PCV and negatively with FEC. Famacha $^{\circ}$ score was only correlated with HG. HG was positively correlated with PCV and negatively correlated with FEC. FEC and PCV were negatively correlated.

Bi-weekly kid body weights from June (initial) to October (final) for the four treatment groups are represented in Fig. 2. Body weight of kids in the GOA treatment showed no significant changes from the initiation of the study to the end (from $13.8 \pm 0.8 \mathrm{~kg}$ initial to $15.7 \pm 0.9 \mathrm{~kg}$ final weights). Weight changes from initial to final in treatment groups in GFC, $\mathrm{CFG}$ and MXD were, respectively, $14.3 \pm 0.8$ to $21.8 \pm 0.9,14.2 \pm 0.7$ to $18.9 \pm 0.8$ and $14.1 \pm 0.7$ to $20.2 \pm 0.7$, where significant changes were observed in each treatment.

The BCS of kids in the GOA and CFG treatments groups decreased during the study (Fig. 3). Even though there was no detectable trend noted in the BCS for goats in the GFC and MXD groups, BCS was generally higher than those observed in GOA and CFG treatment groups.
In all treatment groups there was no detectable trend in Famacha ${ }^{\mathbb{C}}$ score until after week eight of the study (Fig. 4.). After week eight, treatment groups GFC and MXD had lower Famacha ${ }^{\odot}$ score than the treatments GOA and CFG. Treatment groups GFC and MXD had higher PCV levels than goats alone and cattle followed by goats.

Results of FEC in the four treatment groups are shown in Fig. 5. There was no detectable trend between the four treatment groups for FEC due to the high variability of the measurements (large standard errors). However, FEC remained low until week eight of the study and randomly fluctuated thereafter.

\section{Discussion}

Compared to goats grazing alone, goats in mixed and sequential grazing had higher $\mathrm{BCS}, \mathrm{BW}$ and PCV. Mixed and sequential grazing also decreased Famacha ${ }^{(}$ score. Goats following cattle and goats mixed with cattle were heavier. Abaye et al. (1994) reported that lamb daily gain $(0.23 \mathrm{~kg} / \mathrm{d})$, total gain $(23 \mathrm{~kg})$ and weaning weights $(43 \mathrm{~kg})$ were greater $(\mathrm{p}<0.01)$ and target weaning weights were reached $14 \mathrm{~d}$ earlier in the grazing season when both goat and cattle grazed together than when lambs were in pastures with sheep alone $(18 \mathrm{~kg} / \mathrm{d}$, 19 and $38 \mathrm{~kg}$, respectively). The fact that body weights in goats grazing alone decreased initially is most likely due to the goats being stressed because of being introduced to new pastures and an acclimation period.

Mixed grazing of cattle and goats and goats following cattle tended to have result in higher kid BC scores. This is most likely due to the different grazing patterns of the species. Cattle prefer grass and goats prefer trees and shrubs. Cattle graze low to the ground 
leaving taller forage for goats and allowing more forage land utilization by both species.

Goats grazing mixed with cattle have better Famacha $^{(}{ }^{\circ}$ scores. Marshall et al. (2012) suggested that using the Famacha ${ }^{\odot}$ chart (Vatta et al., 2002) would be a suitable approach to monitor control nematode infections in goats in the southeast and the use of the Famacha ${ }^{\circ}$ chart would be a suitable approach for hobby or small limited resources farmers. Sequential and mixed-species grazing can have additional benefits. Because gastrointestinal parasites from goats cannot survive in the stomach of cattle and likewise gastrointestinal parasites from cattle cannot survive in the stomach of goats, sequential and mixed-species grazing has the potential to decrease gastrointestinal parasite loads and delay resistance of gastrointestinal parasites to conventional dewormers. The cattle act as "vacuum cleaners", ingesting the goat worm larvae and preventing them from affecting the goat. This is most helpful when sheep and cattle follow each other in a grazing system such as sequential grazing.

Being that BW was positively correlated $(\mathrm{p}<0.05)$ with, BCS, $\mathrm{HG}$ and $\mathrm{PCV}$ and there was a negative correlation with FEC implies that goats that have a good body weight and good overall condition can counterattack parasitic infections because of a healthier immune system. Famacha ${ }^{\circledR}$ scores were only correlated with HG. There was a trend for Famacha ${ }^{\odot}$ score to be positively correlated with FEC. This is expected as Famacha $^{\circ}$ score increase due to anemia cause by heavy parasite burdens and increased FEC. Fecal egg count and PCV were negatively correlated. Fecal egg counts are expected to increase as animals are infected and PCV values are lower, hence the negative correlation.

\section{Conclusion}

Sequential and mixed species grazing of goat kids and cattle increased growth performance and had a tendency to reduce parasitic loads. A continuation and extension of this research will determine the efficient utilization of available forage resources to further enhance animal performances and to increase farm income per unit area of production under sequential and mixed-grazing systems.

Sustainable forage management systems should be aimed at meeting the nutritional needs of livestock as well as ensuring the continued productivity of forages used as pasture or preserved feeds. Several management practices are possible, including the use of multiple forage species and/or manipulation of forage species to provide herbage at different times of the year. In the current project, we have only concentrated on Bermuda and rye grasses. There are several other forages that can be investigated including lespedeza and clovers. Serecia lespedeza (lespedeza cuneate) contains condensed tannins that could slow the infestation of parasites in goats (Lange et al., 2006). With the increasing cost of fertilizers, clovers can enhance the productivity of the soil and reduce the fertilizer requirements for sustainable production of forage crops. We need to consider the nutritional requirement of cattle and goats to select forage species that adapt well to agroclimatic conditions and to understand the physical properties of the soil and soil fertility management for efficient year round grazing systems. With doing so, we must pay attention to the genetics of the herd. Genetic variability among goats may influence the response to plant extracts (Worku et al., 2009).

Because gastrointestinal parasites from goats or sheep cannot survive in the stomach of cattle and vice versa, multi-species grazing may decrease internal parasite loads. The decreased level of parasites should result in fewer treatments for worms which could slow resistance of parasites to conventional dewormers, an increasing problem with small ruminants. In a field infected with a high load of larvae from sheep and goat parasites, cattle should be grazed first to pick up the larvae of parasites and then goats or sheep could graze with less danger of parasite infestation. In other situations, producers may prefer to have small ruminants graze before cattle as most of the larvae of internal parasites are located on plants within 4 inches of the ground.

Diversification of species results in diversification of income sources. Grazing a pasture with more than one species of animal offers several advantages. For one thing, a mix of different dietary preferences and grazing behaviors results in greater plant utilization; that means heavier stocking rates and increased production from a unit of land. Plus, it helps maintain a better ecological balance among plant species. Cattle and goats have different production cycles. Goats produce kids in early spring and kids are ready for market in early summer. Cattle could produce calves anytime of the year. With the economic climate changing in the agricultural industries, we need to conduct research to discover ways to maximize profit potential while fully utilizing existing resources. Further research should be designed with an integrated approach to assist producers to choose the best alternative management systems that maximize returns in a given market situation. This will allow producers to make use of the benefits provided by each management alternative and to compensate for any production and marketing risk that may arise from using any individual management practice in isolation. Dietary antioxidants from natural herbs such as Andrographis paniculata have the potential to improve feed efficiency, increase lean meat and reduce body internal fat in the carcass of goats (Karami et al., 2010).

Health information gathered from this project can be used by producers to minimize the development of resistance and/or to manage an existing resistance problem by establishing a preventive program on their 
farm. Compared to single-species grazing, multiple species of animals utilize resources more efficiently and uniformly. Cattle and goats have unique dietary preferences and this could result in plant communities that are more resistant not only to grazing impacts but to other factors affecting ecosystem stability, such as drought.

\section{Acknowledgement}

This study is part of a project titled "The performance of cattle and goats under sequential and mixed-grazing systems" which was funded by NIFA/USDA and implemented by Southern University Agricultural Research \& Extension Center (SUAREC). We want to express our sincere appreciation to Mila Berhane, Paul Thomas and Eugene Runles for all their help in the preparation and analysis of this work. The support of the SUAREC Experiment Station in the establishment of the goat herd is also acknowledged.

\section{Funding Information}

This study was funded by United States Department of Agriculture, National Institute of Food and Agriculture (NIFA) under the 1890 Capacity Building program. This Award incorporates the general research terms and conditions (06/11) and NIFA Agency Specific terms and conditions (07/11) as outlined at http://www.nifa.usda.gov/business/awards/awardterms.ht $\mathrm{ml}$. The funders had no role in study design, data collection and analysis, decision to publish, or preparation of the manuscript.

\section{Author's Contributions}

Renita Marshall: Was responsible for sample collection, the writing of the manuscript and managing the manuscript publication process.

Sebhatu Gebrelul: Was responsible for data analysis, interpretation and editing the manuscript.

Shonta Manuel: As a laboratory technician, Ms. Manuel was responsible for the determination of fecal egg counts from fecal samples and packed cell volume percentages from blood samples.

Calvin Adams: Was responsible for data collection and managing the research farm.

Yemane Ghebreiyessus: Was responsible for pasture development and forage management.

\section{Ethics}

The authors have no ethical issue with the publication of this manuscript.

\section{References}

Abaye, A.O., V.G. Allen and J.P. Fontenot, 1994. Influence of grazing cattle and sheep together and separately on animal performance and forage quality. J. Anim. Sci., 72: 1013-1022. PMID: 8014135

Bertelsen, B.S., D.B. Faulkner, D.D. Buskirk and J.W. Castree, 1993. Beef cattle performance and forage characteristics of continuous, 6-paddock and 11paddock grazing systems. J. Anim. Sci., 71: 1381-1389. PMID: 8392043

Chappell, A., S. Gebrelul, V. Bachireddy, O. Udoh and G. Simon, 2004. The effects of mixed-species and grazing management on the performance of Brangus cows: Early Observations. J. Anim. Sci.

Gebrelul, S., A. Chappell, Y. Ghebreiyessus, A. Harris and M. Berhane, 2004. Mixed-species and grazing management effects on the performance of goats: Preliminary Observations. J. Anim. Sci.

Ghebreiyessus, Y., V. Bachireddy, S. Gebrelul, R. Payne and M. Berhane, 2007. The effect of mixed grazing management on forage yield and quality. J Anim. Sci., 85: 294.

Horák, F., K. Chroust, J. Zizlavský and S. Zizlavská, 1999. Study of the possibilities of mixed grazing by cattle and sheep in conditions of the Czech Republic. Livestock Production Sci., 61: 261-265. DOI: 10.1016/S0301-6226(99)00075-5

Karami, M., A.R. Alimon, Y.M. Goh, A.Q. Sazili and M. Ivan, 2010. Effects of dietary herbal antioxidants supplemented on feedlot growth performance and carcass composition of male goats. Am. J. Anim. Vet. Sci., 5: 33-39. DOI: 10.3844/ajavsp.2010.33.39

Lange, K.C., D.D. Olcott, J.E. Miller, J.A. Mosjidis and T.H. Terrill et al., 2006. Effect of sericea lespedeza (Lespedeza cuneata) fed as hay, on natural and experimental Haemonchus contortus infections in lambs. Vet. Parasitol., 141: 273-278.

DOI: 10.1016/j.vetpar.2006.06.001

Marshall, R., S. Gebrelul, L. Gray and Y. Ghebreiyessus, 2012. Mixed species grazing of cattle and goats on gastrointestinal infections of Haemonchus contortus. Am. J. Anim. Vet. Sci., 7: 61-66. DOI: 10.3844/ajavsp.2012.61.66

Marshall, R.W., S. Gebrelul, L. Gray, Z. Augustine and E. Runles, 2009. The effect of mixed species grazing in the determination of gastro-intestinal infections of Haemonchus contortus in Spanish does. Proceedings of the ARD 15th Biennial Research Symposium (BRS' 09), Atlanta, GA, pp: 210.

Nolan, T. and J. Connolly, 1989. Mixed v. mono-grazing by steers and sheep. Anim. Production, 48: 519-533. DOI: $10.1017 / \mathrm{S} 0003356100004049$ 
SAS Institute Inc. 2011. Base SAS 9.3 Procedures Guide. Ist Edn., Sas Inst., ISBN-10: 1607648954, pp: 1773 .

Vatta, A.F., R.C. Kreck, B.A. Letty, M.J. van der Linde and R.J. Grimbeck et al., 2002. Incidence of Haemonchus spp. and effect on haematocrit and eye colour in goats farmed under resource-poor conditions in South Africa. Vet. Parasitol., 103: 119-131. DOI: 10.1016/S0304-4017(01)00586-6
Villaquiran, M., T.A. Gipson, R.C. Merkel, A.L. Goetsch and T. Sahlu, 2004. Body condition scores in goats. Langston University. American Institute for Goat Research.

Worku, M., R. Franco and J.H. Miller, 2009. Evaluation of the activity of plant extracts in Boer goats. Am. J. Anim. Vet. Sci., 4: 72-79.

DOI: 10.3844 /ajavsp.2009.72.79 